\title{
El fuego robado. Literatura y exilio en Sergio Pitol
}

\author{
Víctor Manuel Ramos Lemus ${ }^{1}$
}

\begin{abstract}
This article aims to make a brief presentation of the work of Mexican writer Sergio Pitol (1933 - 2018) from the point of view of exile and journey. Moving away from considering physical dislocation as a generating condition of nostalgia and melancholy, it is intended to reflect on how, according to Pitol, the contact with other languages, cultures and literatures is the basis of the themes and forms of writers productions, thereby enriching the literary tradition they belong to.
\end{abstract}

Keywords: Sergio Pitol; Contemporary Mexican literature; Literature and dislocation; Literature and exile.

Resumen: Este artículo tiene como objetivo hacer una breve exposición de la obra del escritor mexicano Sergio Pitol (1933 - 2018) desde el punto de vista del exilio y el viaje. Intentando ir más allá de considerar el dislocamiento físico como una condición generadora de nostalgia y melancolía, se pretende reflexionar sobre cómo, para Pitol, el contacto con otras lenguas, culturas y literaturas está en la base de los temas y las formas practicadas por los escritores, con lo cual enriquecen la tradición literaria a la que pertenecen. Palabras clave: Sergio Pitol; Literatura mexicana contemporánea; Literatura y dislocamiento; Literatura y exilio.

Pide que el camino sea largo... Detente en los emporios de Fenicia y hazte con hermosas mercancias...

Konstantinos Kavafis. Ítaca

Introducción: Lugares y territorios de la literatura

La "literatura hispanoamericana", expresión constituida de dos nociones equívocas y polémicas, está marcada por un aire de extranjería. Por lo que respecta a la concepción "belles lettres" de la primera, que es la que aquí se cuestiona porque aún es dominante entre la crítica y las instituciones educativas, la persigue la paranoia de sentirse una actividad cultural que no pertenece endógenamente a estas tierras. ${ }^{2}$ Aplicados a la noción de "literatura", conceptos como "ideias fora do lugar", "transculturación", "entre-lugar",

1 Doutor em Teoria Literária pela Universidade Federal do Rio de Janeiro (UFRJ). Professor do Programa de Pós-Graduação em Letras Neolatinas (UFRJ). Projeto de Pesquisa: “As tramas do evento histórico" (UFRJ).

2 Contraponiéndose a esa concepción que la asocia a una filistea "alta cultura", Antonio Candido afirma: "Llamaré literatura, de la manera más amplia posible, a toda creación de orden poético, ficcional o dramático en todos los niveles de una sociedad, en todos los tipos de cultura, desde lo que denominamos folclor, leyenda o chiste, hasta las formas más complejas y difíciles de la producción escrita de las grandes civilizaciones." (CANDIDO, 2004, p. 174 - trad. VL) 
entre otros, suelen arrancar de la premisa de que esa es una práctica bastarda en este lugar del mundo y que por lo tanto necesita justificar su presencia entre nosotros. Indagar sobre sus formas exige siempre explicar la relación que mantiene con influencias europeas y norteamericanas. Al mismo tiempo, la frustración renovada de tentativas de instaurar modos propios de producción y crítica está marcada por una constante sensación de desarraigo. El equívoco y el prejuicio la circundan: el escritor, letrado, escribe para una polis mayoritariamente iletrada -pero no inculta-, y presupone que la "literatura" solamente lo es plenamente en Europa, donde los índices de lectura son estadísticamente mayores. Vista de esa manera, la literatura puede tener una casa en territorio latinoamericano, pero no todas las noches se queda a dormir y soñar en ella.

Por lo que respecta al adjetivo "hispanoamericana", en él se sospecha, por partida doble, cierta mirada de extranjería:

a) venida del exterior, ya que parece representar un esfuerzo por tornar inteligible una pluralidad que resulta ajena e inabarcable, y por lo tanto se hace necesario elaborar una síntesis reductora del "conjunto";

b) interna, en la medida en que los entes implicados liman sus diferencias, operando una depuración sintética, y aceptan sus parciales semejanzas para proyectarse hacia afuera en un concepto reductor y genérico - y dejan sus especificidades irreductibles, su "intrahistoria" como decía Miguel de Unamuno, para sus especialistas "nacionales".

Porque si el Continente, cuyo nombre le viene de afuera, y antes de haber sido visto fue soñado, y sobre él se proyectaron imaginarios utópicos o apocalípticos, era de esperarse que esta tierra empezara a ser escrita con mirada extranjera, de manera que no es de sorprender que en sus Cartas de relación, el castellano Hernán Cortés buscase símiles españoles para la naturaleza fabulosa y extraña que aparecía ante sus ojos (a este respecto, en su Segunda carta de relación, de 30 de octubre de 1520, describe a los herbolarios como "boticas", los templos aztecas como "mezquitas", y habla de frutas y verduras "que son semejables a las de España" - CORTÉS, 2004), y el madrileño Alonso de Ercilla y Zúñiga, en su Araucana, usase la retórica grecolatina para nombrar la fiereza de Caupolicán o la sabiduría de Colo Colo. "Nueva" España, "Nueva” Granada, las múltiples Córdobas, Salamancas o Valladolides autorizan al búlgaro Todorov ${ }^{3}$ y al francés Gruzinski ${ }^{4}$ a decir que, inventado por el ojo extranjero, sus más célebres razonadores siempre vieron al Continente desde fuera.

Otro tanto ocurre con el corpus que constituye su literatura. De Los comentarios reales del Inca Garcilaso, escritos en el exilio cordobés de éste, a las obras paradigmáticas del "Boom", compuestas por latinoamericanos en París, Nueva York o Barcelona, pasando por las polémicas de la lengua ocurridas en Chile (1842) entre el argentino Domingo Faustino Sarmiento y el venezolano Andrés Bello, los ensayos del cubano José Martí

3 TODOROV, Tzvetan. La conquista de América. El problema del otro. Trad. Flora Botton Burlá. $9^{\mathrm{a}}$ ed. México: Siglo XXI, 1998.

4 GRUZINSKI, Serge. La guerra de las imágenes, de Cristóbal Colón a Blade Runner (1492-2019). Trad. Juan José Utrilla. México: Fondo de Cultura Económica, 1994.

5 Denominación que resume mucha de la más significativa narrativa que se produjo en América latina poco después del mediodía del siglo pasado y que fue acuñada con mirada europea. Sus autores se declararon lectores del norteamericano William Faulkner, cuya visión del realismo, según el también norteamericano Fredric Jameson, "desatascó así multitud de tradiciones y favoreció el boom latinoamericano, con su realismo mágico, así como todo tipo de novelas en todo el mundo ajustadas al «programa de escritura» estadounidense." (JAMESON, 2018, p. 208) 
escritos en Nueva York y el modernismo del nicaragüense Darío gestado en su maleta-escritorio entre Buenos Aires, España y París, muchas de las obras y movimientos más significativos están marcadas por el dislocamiento.

El paso del siglo XX al XXI marca la presencia de escritores que no sólo continúan con esa condición de extranjería, sino que la asumen con el orgullo lúdico del que completó con sellos y figuritas de las más variadas geografías las 32 páginas del pasaporte. De Roberto Bolaño para acá (escritor chileno-mexicano-catalán que amenaza convertirse él solo en un período de la literatura "latinoamericana"), cerca del olor a papel recién horneado y de las mesas de cafés y bares donde se construyen mitos y se aciertan contratos de edición o columnas en semanales, Barcelona parece haberse consolidado como el lugar de residencia de la escritura "latinoamericana". Rodrigo Fresán, Juan Gabriel Vázquez, Juan Pablo Villalobos, Edmundo Paz Soldán y otros, con sus estancias permanentes o definitivas, han contribuido a que la ciudad condal se transforme en la sede de los templos tutelares en donde se ofician las misas decisivas de la consagración literaria de los escritores de este lado del Atlántico.

La sensación de extranjería, por otra parte, también se siente en los temas que se incorporan. La necesidad de pensar al continente latinoamericano y su literatura a partir del concepto de "nación" (idea tan europea si se revisan los debates del siglo XIX desde Renan y Taine) hasta la boga de los estudios post-coloniales, son impensables sin los libros del palestino Edward Said, los indios Gayatri Spivak, Homi Bhabha o Arjun Appadurai - autores y obras en los que muchas monografías encuentran asideros conceptuales para fundamentar sus reflexiones sobre obras y autores latinoamericanos.

En todo caso, la cuestión que permanece decisiva es: ¿cómo se explica la relación entre la literatura y el espacio biográfico? Porque es más plausible que el cronotopo de los textos de un escritor se produzca más por la constelación de lecturas que por los lugares que nombra un acta de nacimiento o la credencial para votar. El movimiento físico tampoco define que el lugar donde se habita sea el territorio (en tanto espacio atravesado de intencionalidades, construido por la conciencia, y que no coincide necesariamente con el "lugar" empírico, por más que se proponga copiarlo o ajustarse a sus coordenadas) que la escritura construye. Casos como los de Nabokov, Conrad, B. Traven y otros escritores exofónicos ${ }^{6}$, cuyas obras no sólo no están escritas en ruso, polaco o alemán, ni ocurren en las estepas siberianas, la nublada Varsovia ni en el verde germánico de la Schwarzwald, son los casos extremos que explicitan que el territorio de la literatura es otro, y no siempre es identificable por un código postal.

¿Cómo pensar entonces la identidad y la autenticidad de nuestra literatura?

Esas y otras preguntas pueden ser abordadas de manera productiva en la obra de Sergio Pitol.

\section{Autoconstrucción de una "figura de autor"}

El viaje - título del segundo libro que compone su Trilogía de la memoria - es lo que define la obra de Sergio Pitol. Desde la caricatura canónica de Rogelio Naranjo hasta la

6 Término que se refiere a escritores que tras haber aprendido una lengua en edad adulta (no necesariamente son "bilingües"), escriben en ella e inclusive se insertan en su sistema literario y cultural. 
de Helioflores, su imagen es asociada al dislocamiento, que siempre presupone la vuelta cargando los tesoros acumulados en sus diversas estancias - lenguas aprendidas, libros traducidos, obras escritas en las que se revela lo adquirido en el contacto con otras culturas. Quizá por eso, Elena Poniatowska (recuperando la provocación del gentilicio: francesa de origen polaco llegada a México a los 11 años, y una de las figuras centrales de la literatura mexicana del siglo XX) ha dicho que Sergio Pitol era el escritor de todos los regresos. Sin embargo, la distancia se vuelve un disparador que lo conduce a las raíces: "el viaje representa en Sergio Pitol un alejamiento que sin embargo lo retrotrae a lo más profundo de sí mismo, a la niñez, la memoria, el pozo del que surge todo" (GARCÍA BERGUA, 2018, p. 6)

La dimensión nostálgica del viaje lo persiguió desde sus orígenes familiares: descendiente de italianos, nacido en Puebla y criado en el ingenio azucarero de Potrero, Veracruz, como un huevo larvado de nostalgia, en su niñez sin padres (junto con su hermano, fue criado por la abuela materna y un tío), creció soñando con el Véneto.

Un balance de su cultura de infancia revela que siempre estuvo signado por el dislocamiento: ópera italiana en casa (influencia perceptible en muchas de sus obras, como lo ha demostrado Alfonso Colorado ${ }^{7}$ ), novelas de Julio Verne, Stevenson y Salgari, el castellano de casa y de la calle que se mezclaba con las lenguas que hablaban los administradores y técnicos del ingenio azucarero.

De acuerdo con su propio testimonio, en su infancia sufría de constantes fiebres tercianas, provocadas por el paludismo que contrajo a los ocho años, y que lo persiguieron hasta los doce. Dos eran las ventanas hacia el mundo de que disponía: una, el balcón del cuarto en el que dormía y daba a la exuberante vegetación veracruzana; la segunda, los libros que circulaban en la casa familiar. ("Historias de vida. Sergio Pitol.", 2014, 8' 10") ¿Cómo se desarrollarían en su imaginación las aventuras rusas de Miguel Strogoff bajo el sopor alucinante de las fiebres del Golfo de México? ¿Cómo reconstruía en su conciencia los dislocamientos de puntualidad británica del flemático Phileas Fogg y el jovial Passepartout a través de paisajes de fabuloso exotismo? Muchos de sus testimonios (en los que se advierte la preocupación por cimentar una figura de autor $\mathrm{y}$, a la manera de Borges, construir el horizonte a partir del cual quería ser leído) sugieren la imagen de un Alonso Quijano en el trópico, cuya única relación con el mundo se encontraba mediada por los libros. Eventualmente, cuando la fiebre le daba alguna tregua, iba al cine a ver las adaptaciones hollywoodianas de las novelas de aventuras que poblaban su imaginación.

Hacia el final de su adolescencia, migra a la Ciudad de México para estudiar Derecho. Junto con otros célebres compañeros de promoción, como Carlos Fuentes y Víctor Flores Olea, se beneficia de las enseñanzas del profesor sevillano Manuel Martínez de Pedroso, un "transterrado" 8 a quien homenajea en su discurso de la obtención del Premio Cervantes de literatura en el 2005. Gracias a él, a partir de ejemplos extraídos de la literatura, apren-

7 "La ópera aparece de mil maneras. En 1977 en La Palabra y el Hombre se publicó "La ópera: música en acción” de Michel Leiris, traducida por Pitol. Uno de sus personajes más memorables, Billie Upward, hace furiosas disquisiciones sobre Las bodas de Fígaro de Mozart en Juegos florales (1982). "Don Giovanni: ese dramma giocoso", abre Pasión por la trama (1998)." (COLORADO, 2018, p. 70)

8 Inventado de manera improvisada por José Gaos en una cena con profesores mexicanos de la Facultad de Filosofía y Letras de la UNAM en 1943, el término se refiere a la condición de los profesores republicanos que, expulsados de España durante la Guerra Civil, fueron acogidos en México. Miguel León-Portilla escribe a ese respecto: "Quiso él introducir así una tajante distinción. "Desterrado" es el que tiene que dejar su patria y pasa a lugar que le es ajeno. En cambio, "transterrado" es quien, teniendo que salir de su tierra, se establece en otra que le es afín y en la que llega a sentirse "empatriado" (LEÓN-PORTILLA, 1989) 
día los meandros y las contradicciones de la jurisprudencia ${ }^{9}$ - lo que agudizó aún más en él su naturaleza de animal literario. Todo eso le mostró, como él mismo se encargó de reiterar, las particularidades del territorio de la literatura.

Las décadas de 1930 y 1940 del siglo veinte mexicano son años de reconstrucción de un país marcado por el nacionalismo posrevolucionario. La centralidad de la "novela de la revolución" (encabezada por la obra de Mariano Azuela y Martín Luis Guzmán), el muralismo de Diego Rivera, José Clemente Orozco y David Alfaro Siqueiros, y la música de Silvestre Revueltas, definen la imagen de un país cultural y políticamente efervescente, que intenta hacer un profundo ajuste de cuentas con su identidad. En el caso de Sergio Pitol, fatalmente el himno patrio tenía que ser paladeado de otra forma: bajo la efigie tutelar del águila y la serpiente, la semejanza entre las banderas italiana y mexicana debería marcar el espíritu, al mismo tiempo, de síntesis y extrañamiento - contradicción que también se encuentra en su obra.

Sin embargo, los años en los que la historiografía literaria lo sitúa coinciden con un país que intenta resolver sus contradicciones. La suya es la "Generación del Medio Siglo" o "De La Casa del Lago" porque en esa casona de Chapultepec, fundada el 15 de septiembre de 1959 por Juan José Arreola bajo auspicios de la Universidad Nacional Autónoma de México (UNAM), jóvenes escritores se reunían para leer Poesía en "Voz Alta". ${ }^{10}$ Marcados por el cosmopolitismo (a fin de cuentas, el presidente emblemático del período sintetiza el carácter contradictorio de esos años: encargado de desarrollar la industria nacional con la implementación de una política de "sustitución de importaciones", Miguel Alemán, por su acentuado norteamericanismo, era conocido como "Míster amigo"), se trata de escritores que frecuentan otras lenguas y culturas. Así como Jorge Ibargüengoitia traducía del inglés y Juan García Ponce del alemán, serán notables y disputadas por grandes casas editoriales las traducciones que Pitol hizo del inglés, del ruso, del italiano y del polaco.

Sin embargo, la década de 50 es también el momento en que se producen muchas de las obras paradigmáticas en que, bajo el signo del nacionalismo, se diserta sobre "lo mexicano": Pedro Páramo (1955) y los cuentos de El llano en llamas (1953) de Juan Rulfo; El laberinto de la soledad (1950) de Octavio Paz; Los grandes momentos del indigenismo en México (1950) de Luis Villoro; Análisis del ser del mexicano (1952), de Emilio Uranga. El colmo de la paradoja está en que el grupo Hiperión quizá sea el más emblemático de este debate: formado por españoles transterrados (José Gaos, Luis Villoro, Emilio Uran-

9 "Pedroso solía hablarnos del dilema ético encarnado en «El gran inquisidor», de Dostoievski; del antagonismo entre obediencia al poder y el libre albedrío en Sófocles y Eurípides; de las nociones de teoría política expresadas en los tantos Enriques y Ricardos de los dramas históricos de Shakespeare; de Balzac y su concepción dinámica de la historia; de los puntos de contacto entre los utopistas del Renacimiento con sus antagonistas los teóricos del pensamiento político, los primeros visionarios del Estado Moderno: Juan Bodino y Thomas Hobbes. A veces en la clase discurría ampliamente sobre la poesía de Góngora, poeta que prefería a cualquier otro del idioma, o de su juventud en Alemania, donde había realizado la traducción al español de poemas de Rilke, algunas obras de Goethe y también la de Despertar de primavera, de Franz Wedekind, uno de los primeros dramas expresionistas que circuló en el ámbito hispánico.” (PITOL, 2005)

10 "Poesía en Voz Alta, movimiento patrocinado por la Dirección de Difusión Cultural de la UNAM, a cargo de Jaime García Terrés, y bajo la coordinación del Teatro Universitario de Héctor Mendoza (1932). Los primeros directores del grupo fueron Octavio Paz y Juan José Arreola. Las representaciones de Poesía en Voz Alta se hacían principalmente en el teatro El Caballito, la Casa del Lago (fundada en 1959) y el Teatro Moderno.” (ROSADO; CASTAÑÓN, 2008, pp. 295 -296) 
ga, Jorge Portilla, Ricardo Guerra, Joaquín Sánchez McGregor, Salvador Reyes Nevárez, Leopoldo Zea y Fausto Vega y Gómez), abordaban la cuestión de la identidad a partir de la síntesis entre nacionalismo y cosmopolitismo - algunos de sus filósofos, como Eduardo Nicol y el propio Luis Villoro, notables heideggerianos, pensaban el ser-ahí (corporificado en la figura del "mexicano") en la modernidad capitalista.

Por esos años, es en un barco rumbo a Venezuela que Pitol empieza a escribir poesía y relato, inaugurando un hábito que marca su obra: la escritura en dislocamiento: "Para mí el movimiento físico, es un estímulo brutal; todas mis cosas han sido escritas siempre en algo que se mueve: en viajes largos por tren, por barco, y aun en los tranvías. Me gusta escribir durante el desplazamiento, mientras todo va cambiando a mi alrededor." (PITOL apud DABROWSKA, 2018, p. 13)

De acuerdo con su propio testimonio, desde muy joven comienza su vida viajera, por Nueva Orléans, Cuba y Venezuela (“Palabra mayor”, 2017, 15'57”), país este último donde empieza a escribir ("Más cultura", 2015, 10'10"). Sin embargo, es a los 21 años que, tras concluir sus estudios de Derecho y cursar Letras en la Facultad de Filosofía y Letras de la UNAM, empieza su periplo itinerante en un viaje que lo lleva de Londres y París a Italia, y de ahí a Pequín y Varsovia, donde permanecerá por un buen tiempo. Posteriormente se conducirá a Barcelona, a Bristol, y de ahí a París, como agregado cultural. Finalmente, será embajador en Praga. Con intermitentes vueltas a México, su estancia europea durará hasta 1993, cuando decida instalarse definitivamente en la ciudad de Xalapa, Veracruz, hasta su muerte en 2018.

Su vida fuera de México se divide en dos etapas. A la primera corresponde la del "freelancer" que se sostiene de la traducción y la organización de colecciones literarias (en los años setenta dirige Los Heterodoxos para la catalana Tusquets) y es lector de español en la Universidad de Bristol (1971). En la segunda, pertenece al cuerpo diplomático mexicano: será agregado cultural en Varsovia y París, y más tarde embajador en Praga durante seis años.

Los oficios de Pitol siempre han tenido que ver con la literatura. Ha sido traductor, editor, corrector de pruebas, secretario, consejero editorial. El discurso en que construye su "figura de autor" asienta en la afirmación de que su vida siempre estuvo marcada por la lectura, y eso es lo que lo define, no sólo a él como hombre de letras, sino a muchos de sus personajes y a las situaciones que se encuentran en sus relatos.

En El último lector, Ricardo Piglia afirma que el lector de ficciones "es alguien que encuentra en una escena leída un modelo ético, un modelo de conducta, la forma pura de la experiencia." (PIGLIA, 2005, p. 105) En Sergio Pitol, el lector y la figuración del acto de la lectura definen un modo de escribir. En El arte de la fuga, texto híbrido que abre la cuarta etapa de su obra, en la que ficción, ensayo y memoria se entrelazan, afirma:

Uno, me aventuro, es los libros que ha leído, la pintura que ha visto, la música escuchada y olvidada, las calles recorridas. Uno es su niñez, su familia, unos cuantos amigos, algunos amores, bastantes fastidios. Uno es una suma mermada por infinitas restas. Uno está conformado por tiempos, aficiones y credos diferentes. En el momento en que escribo estas páginas puedo dividir mi vida en una fase larga, gustosa y gregaria, y otra, la más reciente, en que la soledad me parece un regalo de los dioses. (PITOL, 2007a, p. 42)

Y es por lo tanto bajo el signo de la lectura que la obra de Sergio Pitol, de manera explícita, se gesta. De acuerdo con él, leer es dejarse colonizar, durante la lectura, por voces ajenas, frecuentemente más desaforadas que la propia imaginación. En ese acto, el lector 
más generoso (inigualables en este punto son las figuraciones literarias de Alonso Quijano y Emma Bovary), inmerso en su vida marcada por la banalidad de lo cotidiano, llega a empatizar con el texto y experimenta la pasión de la venganza de Edmundo Dantés o los tormentos de Raskolnikov. Pitol confiesa haberse relacionado con el mundo a partir de la actitud de lector. Una anécdota resume todo lo que ahí se encuentra cifrado: cuando era niño, en una revista que llegaba a Potrero, vio "Los peces rojos" (1911) de Henri Matisse. En El viaje, afirma:

Nada había visto tan deslumbrador como aquella página colorida. Un cuadro bañado de luz, iluminado desde arriba, pero también desde el interior de la tela. En una pecera nadaban unos cuantos peces rojos cuyo reflejo se mecía en la superficie del agua. Era el triunfo absoluto del color. El cubo que contenía los peces formaba parte del eje vertical del cuadro y se apoyaba en una mesa redonda sostenida por un solo pie. Estaba, claro, en el centro. Todo el resto de la tela era una selva de hojas hermosas y de flores; estaban en el primer plano, en el fondo, se las veía a través del cristal del recipiente, enardecidas, arracimadas, luminosas, perfectas. Si hubiese vivido en la Antártida, o en el corazón de Sonora, o del Sáhara, donde nadie nunca ve flores ni peces ni agua, podría comprender que aquella precipitación florida me hiciera enloquecer. Pero vivía en Córdoba, al lado de Fortín de las Flores, en medio de jardines suculentos, y aun así aquello me parecía un milagro. (PITOL, 2007b, p. 388)

Igual que a Alonso Quijano, que gracias a los libros de Caballería los polvorientos y yermos caminos de La Mancha se transformaban en espacio de fabulosa aventura, es curioso que para Sergio Pitol la exuberante vegetación veracruzana, cuyo colorido debía saturar hasta a la más acrecentada imaginación, fuera poco comparada con la representación pictórica.

Para él, la idea de la percepción del mundo como literatura se encuentra en la manera en que el realismo es pensado. En sus textos, desde la construcción del relato hasta las situaciones y las formas empleadas tienen que ver con una idea de la escritura como texto, no como copia de lo real. Sobre ese rasgo generacional, su amigo Carlos Monsiváis afirmó:

Si "la novela realista presentaba los acontecimientos con la intención de que parecieran naturales" (Jean Franco), la narrativa contemporánea declara abolidas la fidelidad monogámica a las tendencias establecidas y la lealtad a sentimientos de "desarraigo" (cosmopolitismo) y de "culpa" (realismo social), mientras declara anacrónico el oficio del "amanuense de la realidad”. (MONSIVÁIS, 2010, p. 366)

Sin embargo, la traducción es quizá el desafío mayor para un lector, quizá mucho mayor que el del reseñista, el del editor que da consejos al escritor en ciernes, el del crítico literario ${ }^{11}$ e incluso el del profesor - figuras que en diferentes grados se hunden en la obra para intentar reconocer sus más sutiles mecanismos y resortes. El traductor "es algo más que un lector y algo menos que un autor." (VILLORO, 2001a, p. 95) A ese respecto, Pitol dijo que traducir le permitía adentrarse en la carpintería de un texto, percibir de cerca los más imperceptibles pero decisivos elementos a través de los cuales un escritor construye la delicada máquina de producir sentido y efecto que es la obra literaria.

11 Graciela Speranza recuerda que al final del prólogo de La narración-objeto, Juan José Saer afirma que la crítica literaria "es una forma superior de la lectura, más alerta, más activa, y que, en sus grandes momentos, es capaz de dar páginas magistrales de literatura.” (SAER apud SPERANZA, 2008, p. 134) 
Es posible afirmar que, en cierta medida, la traducción ha sido para Pitol el gran laboratorio de su escritura. Traductor de más de cien autores para las principales casas editoriales españolas que se formaron en los últimos años del franquismo, como Tusquets y Anagrama, gracias a él, en español se ha podido leer escritores como Witold Gombrowicz, Antón Chéjov, Boris Pilniak, Malcolm Lowry, Ronald Firbank, Jerzy Andreievsky, Ford Madox Ford, Joseph Conrad, Henry James, Luigi Malerba, Tibor Déry, Vladimir Nabokob, Kazimierz Brandys, entre muchos otros.

Sobre la importancia que para un escritor representa el contacto con otros idiomas, Juan Villoro ha escrito:

El encierro con un espectro extranjero alerta los reflejos, obliga a una saludable paranoia: el idioma se mantiene en forma, perseguido por otro. La frecuentación y aun el acoso de una lengua extranjera agudiza la propia. (VILLORO, 2010, p. 96)

Que traducir es exiliarse o salir de sí, en Pitol ese comentario no tiene un sentido figurado: gracias al oficio de traductor, podía moverse de un lugar a otro, ya que, como él mismo afirmaba, para traducir sólo necesitaba una máquina de escribir y unos cuantos diccionarios. ("Historias de vida", 2014, 23'03") Pero la metáfora de la traducción como viaje adquiere toda su fuerza en un hábito en su estancia catalana: por unas cuantas pesetas, era frecuente que tomara una habitación sobrante de algún barco carguero del que no sabía su destino. Traduciendo en alta mar, al cabo de algunos días o semanas volvía de esa tierra de nadie con uno o varios libros traducidos. (VILLORO, 2016, 17' 20”)

Subvirtiendo el adagio orteguiano, para Pitol traducir era "dejar de ser uno y su circunstancia", era salir de sí mismo, dejarse habitar por otras ideas, otra voz, otra dicción y otro imaginario; leer para traducir, en su caso, era hundirse en las manías, los tics y el estilo de otro autor para beneficiarse de él - como es frecuente observar en su caso. Ciertamente era en eso que pensaba Walter Benjamin cuando citaba a Rudolf Pannwitz a respecto de lo que traducir podía contribuir a la lengua de llegada: "Nuestras versiones, incluso las mejores, parten de un falso principio: quieren germanizar el sánscrito, el griego y el inglés, en vez de sanscritizar, helenizar y anglicizar el alemán. [...] es necesario ampliar y profundizar la propia lengua gracias a la lengua extranjera." (PANNWITZ apud BENJAMIN, 1971, p. 274 - trad. VL) En el caso de Pitol, podría decirse que ese proceso llegaba incluso a niveles fisiológicos: "Para traducir bien, no basta con dominar las dos lenguas en contacto. Es necesario que el traductor capture la respiración del autor, su ritmo de respiración. Sin eso, estamos ante una traducción muerta" ("Charlando con Cervantes", 18' 55")

En el caso del proceso de escritura, el ejercicio era semejante. Según afirmaba, en su casa podría corregir y elaborar la versión definitiva de sus libros, pero no la primera: en esa era necesario estar fuera de sus hábitos cotidianos, vivir en la ostranenie de sí mismo. Este oficio de extranjería influencia toda su literatura. Si ya desde los 20 años escribió sus primeros poemas en un barco rumbo a Venezuela, más tarde esta práctica se hizo dominante: El tañido de una flauta fue escrita en Bristol, Inglaterra; Juegos florales, en Barcelona; los cuentos Nocturno de Bujara, Vals de Mefisto, El relato veneciano de Billie Upward y Asimetría, en Moscú; El desfile del amor y casi toda la Trilogía del Carnaval, en Praga. Asumiendo su permanente condición de dislocado, incluso de sí mismo, vuelve a Xalapa en 1993 porque, según él: "Necesitaba volver a la lengua. Sin esa lengua, su lenguaje, habituado a ser minoritario, se habría empobrecido." ("Historias de vida", 38' 35") 
Es en Veracruz donde comienza su cuarta etapa, a la que pertenecen El arte de la fuga (1996), El viaje (2000) y El mago de Viena (2005).

Los especialistas han agrupado los títulos mencionados bajo el denominador de Trilogía de la memoria ante la dificultad de encasillarlos dentro de un determinado género. Y es que los tres escapan a cualquier esquema porque las posibilidades de interpretarlos son innumerables. En conjunto, los textos pueden considerarse autobiografía, ensayo, crónica, memoria, ficción, homenaje, poética, reflexión..., incluso "novela", según la propuesta del investigador Ricardo Pace respecto a El arte de la fuga. (MUÑOZ, 2018, p. 41)

En esas obras, la idea de viaje sigue presente. Sin embargo, aquí se trata de un dislocamiento en el tiempo, un escarbar en los recuerdos para transformarlos nuevamente en experiencias, potenciados ahora no sólo por el balance que los años han permitido elaborar, sino también por las referencias culturales que a ellos puede asociar Pitol. Sobre lo que esos textos representan de rescate de la memoria, Juan Villoro ha escrito:

En una tarde que podemos imaginar bañada por el resplandor mediterráneo, Platón consideró que todo conocimiento es una forma del recuerdo. Aprender, adentrarse en el misterio de las cosas, significa establecer contacto con una luz que regresa. [...]

La obra de madurez de Sergio Pitol se ha basado en los reveladores trabajos del recuerdo. [En sus textos,] el narrador no regresa a un entorno que domina de antemano; por el contrario, descubre recuerdos sorpresivos. (VILLORO, 2007, p. 17)

Porque en Pitol, recordar es viajar hacia adentro y hundirse en saberes quizá desconocidos para sí mismo. Así, el viaje (exterior) y el recuerdo (interior) convergen al producir experiencias dislocadas: “A fin de cuentas, el viaje es siempre interior. Por más turísticos que sean nuestros paseos, los desplazamientos mueven en nosotros fuerzas subconcientes, la memoria cambia sus fichas cuando se modifica la noción de tiempo." (GARCÍA BERGUA, 2018, p. 7) Trasvasadas al ejercicio de la escritura, la sensación de extrañamiento se acrecienta: "Ser escritor es convertirse en un extraño, en un extranjero: tienes que empezar a traducirte a ti mismo. Escribir es un caso de impersonation, de suplantación de personalidad: escribir es hacerse pasar por otro." (PITOL, 2007a, p. 142) Sin embargo, esa condición también conoce instantes de clímax: "Los momentos de excepción en la literatura se producen cuando el autor, sea cual sea el curso que siga al iniciar una obra, logra sumergirse en las corrientes profundas del lenguaje para, de esa manera, perder sus propias señas de identidad.” (PITOL, 2007a, p. 184)

Por lo tanto, la práctica de la lectura, la traducción y la escritura aparecen como un estado de excepción de sí mismo. En el tránsito de la expresión a la comunicación, en el intento de transformar las intuiciones y pulsiones personales en objeto que pueda ser compartido por una colectividad de lectores, el escritor se encuentra en estado de extrañamiento.

Y esa es la manera en que se construyen los relatos de Sergio Pitol.

\section{Literatura: derrota de la literalidad}

Quizá el más alto logro de la literatura sea su derrota de la literalidad. Inclusive, los injustamente criticados "realistas" (y, de acuerdo con Pierre Bourdieu en Las reglas del 
arte, mal comprendidos ${ }^{12}$ ), piedra en el zapato de la crítica literaria, con su cuidadísima elaboración estética llevan a su máxima expresión el "como si" en que consiste todo arte.

En su excelente reflexión sobre La ascensión de la novela, Ian Watt afirma que la pasión por las cosas concretas, y el consecuente abandono de los universales arquetípicos, fue el requisito que posibilitó el surgimiento del realismo literario. ${ }^{13}$ que jamás es mera copia de lo que es exterior a los sentidos (si esto fuera realmente posible), sino estilización, artificio que depende de la capacidad, limitaciones y perspectiva de un sujeto determinado ideológica, geográfica, cultural e históricamente. La técnica del trampantojo no es sino una forma artificial que organiza la percepción del observador para que vea en la tela, por ejemplo, paisajes que la realidad no ofrece.

En su ensayo Direito à literatura, Antonio Candido afirma que la literatura le da forma a la experiencia. La obra de Sergio Pitol asume eso con radicalidad, y todo pasa a ser visto bajo esa forma artística.

Quizá los cuatro años de fiebres tercianas en los que el delirio confundía la percepción de la realidad con las lecturas de Julio Verne (condición en la que la literatura y la vida barajaban sus leyes, o una permitía iluminar mejor a la otra) fueron decisivos, como sugiere en ese discurso de autor que es El arte de la fuga, para definir no sólo su pasión por la literatura, sino su manera de ejercerla. Si la historia del conocimiento consolidó los privilegios de la vista, y el ojo se transformó en el órgano que resume la metáfora del conocimiento en Occidente ("ser ciego" es no entender, no percibir - Edipo, el hombre que no supo entender los signos, se arranca los ojos), la obra de Sergio Pitol trabaja con los sentidos trastocados. En "Todo está en todas las cosas", ensayo memorialístico y de ficción al mismo tiempo, cuenta su primer viaje a Venecia, la tierra de sus abuelos. Al bajar del tren, en esa mañana de 1961, y dejar su maleta en consignación para poder pasear durante el día, verifica con estupor que ha perdido sus lentes. El azoro era comprensible: en su condición de miope, ¿cómo observar una ciudad que parece hecha para una fiesta del ojo?

A pesar de extenso (colocado para que el lector de lo hasta aquí expuesto y que no posea el ejemplar de Pitol pueda conversar con este ensayo), en el siguiente fragmento puede apreciarse la intensidad con que el autor veracruzano recuerda "haber experimentado" sus primeros pasos en la ciudad de los canales:

De pronto me encontré en la Piazzeta, dispuesto a comenzar mi recorrido. Mi miopía de ningún modo atenuó el deslumbramiento. Llegué a la Plaza de San Marcos y tomé mi primer café en Florian, el legendario lugar reseñado por todos los escritores y artistas que alguna vez visitaron Venecia. Compré, a un lado de Florian, una guía turística. Ver de cerca, leer, por ejemplo, no me presentaba mayor problema. Después del café, guía en mano, comencé a caminar. Se me escapaban los detalles, se desvanecían los contornos; por todas partes surgían ante mí inmensas manchas multicolores, brillos suntuosos, pátinas perfectas. Veía resplandores de oro viejo donde seguramente había descascaramientos en un muro. Todo estaba inmerso en la neblina como en las misteriosas Vedute de Venezia, coloreadas por Turner. Caminaba entre sombras. Veía y no veía, captaba fragmentos de una realidad mutable;

12 "La palabra "realismo", sin duda casi tan vagamente caracterizada, en las taxonomías de la época [mediados del siglo XIX], así como sus equivalentes de hoy..." (BOURDIEU, 1996, p. 93 - trad. VL. Aconsejo lectura de las páginas siguientes para acompañar el debate que el pensador francés hizo de autores como Baudelaire, Flaubert y otros a propósito del "realismo")

13 Consúltese especialmente el primer capítulo: "O realismo e a forma do romance”. (WATT, 2010, pp. 9-36.) 
la sensación de estar situado en una franja intermedia entre la luz y las tinieblas se acentuó más y más cuando una fina y trémula llovizna fue creando el claroscuro en el que me movía. A medida que la niebla me velaba aún más la visión de palacios, plazas y puentes mi felicidad crecía. Caminé tanto que aún hoy me queda la impresión de que aquel día incorporó una inmensa multitud de días. En la marcha, extasiado, repetía una y otra vez una frase de Berenson: «El mayor regalo que nos han dado los venecianos es el color», palabras que recordaba haber leído al inicio de Los pintores venecianos del Renacimiento. Vuelvo hoy al libro a ratificar la cita y encuentro que no sólo le había hecho perder su entonación, sino deformado y contraído, como sin duda pasó con todo lo que descubrí en Venecia en ese encuentro inicial. Berenson escribe: «Their mastery over colour is the first thing that attracts most people to the painters of Venice. Their colouring not only gives direct pleasure to the eye, but acts like music upon the moods, stimulating thought and memory in much the same way as a work by a great composer». La reducción de la cita intentaba aproximarse a su contenido. Sí, el color, ese gris preponderante que percibía, con fondos ocres, rojos de Siena, verdes botella y constantes dorados se convertía no sólo en fuente de placer para mis ojos maltrechos, sino que estimulaba la mente, la imaginación y la memoria de modo extraordinario.

Entré en San Marcos; la inmensidad del espacio me dejó sobrecogido. Durante un buen rato seguí a un grupo a quien un guía de turistas explicaba en francés con morosa pedantería ciertas características del arte bizantino. En aquel fastuoso espacio tuve el único momento de duda de ese día. Me parecía difícil aclararme si aquella grandeza era un signo evidente del esplendor de Bizancio, o un camino hacia la estética de Cecil B. de Mille, ese triunfo de Hollywood. (PITOL, 2007a, pp. 30 - 31)

Con la vista reducida, Venecia se le presenta como un espacio fantasmal, habitado no sólo por los recuerdos y el idioma que invadía sus oídos en la infancia ("el italiano era un idioma corriente en casa" - "Historias de vida. Sergio Pitol”, 2014, 20'18”), sino también por la pintura, la literatura, el cine - suma de discursos y representaciones que enriquecen y hacen posible "ver". Como puede apreciarse en la extensa cita, Venecia es el oro viejo con que sus palacios son descritos, la pátina de las pinturas, la opinión de célebres artistas y viajeros, la representación que el fastuoso cine hollywoodiano ha hecho de esta ciudad en que Thomas Mann, Shakespeare y otros notables escritores han ambientado historias fundamentales de la literatura europea. A pesar de que en Las ciudades invisibles Italo Calvino advierta que "no se debe confundir la ciudad con el discurso que la describe" (CALVINO, 1983, p. 42), no se puede ignorar que éste influencia y enriquece su percepción, haciéndola más compleja e incluso "completa". Si no, ¿qué otro sentido tiene la expresión "se convertía no sólo en fuente de placer para mis ojos maltrechos, sino que estimulaba la mente, la imaginación y la memoria de modo extraordinario."?

Es así como Venecia se transforma en una ciudad cargada de experiencias de la que Pitol extrae la idea compleja de la literatura como extrañamiento y familiaridad al mismo tiempo. Contra cierta aspiración novelística que busca en el género una aproximación al documental, que necesita del máximo de "adecuación entre el intelecto y las cosas" que, según Heidegger, caracterizaba el conocimiento de la historia de la metafísica (falacia que el reciente concepto de "docuficción" intenta subsanar), para Pitol ver a medias, o torcido, sirve para llegar a una verdad acaso más significativa y honda.

Así, escribir consiste en leer en las entrelíneas de las cosas, escuchar el susurro de lo que no está explicitado, tomar por bueno el malentendido (o "malvisto"). Y como de literatura se trata, y no de puro "testimonio", Sergio Pitol le reserva al lector de su ensayo escrito en 1996 en Xalapa, Veracruz, la siguiente revelación: 
Esa noche, al subir a mi vagón creía conocer Venecia como la palma de mi mano. ¡Qué iluso pobre diablo! La fatiga me vencía; sentí de golpe el esfuerzo brutal realizado durante el día; me dolían los ojos, las sienes, la nuca, todas las articulaciones. Abrí como pude la maleta en busca de un pijama. Lo primero que saqué fue una chaqueta; el tacto me anunció que en uno de sus bolsillos estaban mis lentes. El milagro se había consumado: había cruzado el umbral, el acerado huevo de Leda comenzaba a romperse y en el fondo de las sepulturas se fundían los contrarios. ¿De dónde me venía esa verba esotérica? No terminé de ponerme el pijama. Recordé una frase que está al final de Al faro: «Sí, también yo he tenido mi visión», y me quedé dormido. Volví a repetirla por la mañana, al despertar, cuando ya el tren estaba a punto de llegar a Roma. (PITOL, 2007a, p. 32)

Esta condición, que atraviesa la obra de Sergio Pitol, ha posibilitado que Juan Villoro afirme que su narrativa "no busca aclarar, sino distorsionar lo que mira". (VILLORO, 2001b, p. 52)

Sergio Pitol solía relatar en muchas de sus entrevistas que una de sus primeras influencias formadoras como lector en la adolescencia fue la obra de Juan Carlos Onetti. En $\mathrm{La}$ vida breve, en la soledad de su habitación, Juan María Brausen, a partir de lo que oye a través de la pared, construye la narración de lo que el lector "ve" respecto a Gertrudis, su amante ocasional. El artificio de Onetti es revelador de un frecuente mecanismo que la lectura opera: ella nos incita a creer que imaginamos a partir de la vista, a pesar de que otros sean los sentidos generadores de la experiencia. Obra maestra del oído, la novela del escritor uruguayo evidencia que este órgano es también un disparador fecundo de la literatura.

En "El oscuro hermano gemelo" (al mismo tiempo cuento, ensayo y testimonio), tras reflexionar sobre el hecho de que escribir es salir de sí, imagina la siguiente situación literaria:

Puedo imaginarme a un diplomático que fuese también un novelista. Lo situaría en Praga, una ciudad maravillosa, ya se sabe. Acaba de pasar unas vacaciones largas en Madeira y asiste a una cena en la Embajada de Portugal. La mesa es de una elegancia perfecta. A la derecha del escritor se sienta una anciana dama, la esposa del embajador de un país escandinavo; a su izquierda, la esposa de un funcionario de la Embajada de Albania. El tono de la embajadora es autoritario y decidido; habla para ser escuchada en todo el sector de la mesa que queda a su alcance. (PITOL, 2007a, p. 144)

La situación está dada: mientras que del lado derecho el torrencial y autoritario monólogo de la esposa del embajador, verdadero sonido y furia, le resulta antipático, y a los comensales de ese lado también, ya que a la primera oportunidad se escabullen, del lado izquierdo le llegan los comentarios escuetos de la albanesa sobre la comida ("Is good"), que a él le resultan encantadores. Y aclara:

Que sólo dos palabras conformaran una conversación lo hacía inexpresablemente feliz, porque era sordo del oído izquierdo y la conversación por ese costado le resultaba por lo general una tortura; a menudo se producían malentendidos, sus respuestas no coincidían con las preguntas; en fin, una verdadera lata. (PITOL, 2007a, p. 147)

Más tarde, ese novelista-diplomático transmutará en literatura el torrencial y resentido discurso que escuchó del lado derecho en un relato aún más cruento, cargado de sorna e ironía. A partir de ese episodio de las dos voces (una elocuente y falta de interés, y otra escueta y sugerente), y de dos maneras de escuchar (una, registrando minuciosamente 
cada detalle, y otra que más que oír exige inferir y completar), Pitol reflexiona sobre lo que para él es hacer literatura:

Un escritor a menudo oye hablar sin escuchar una palabra; otras voces lo tienen atrapado. La voz de una persona real desaparece y se convierte en mera música de fondo. A veces unas cuantas palabras lo remiten a tal o cual personaje imaginario. Otras, ¡y allí está lo sorprendente!, ni siquiera el escritor sabe que las voces que trata de incorporar a un personaje, o a una trama, no están destinadas a ese relato, que bajo esa trama existe agazapada otra, que lo aguarda. (PITOL, 2007a, p. 151)

Así como Beethoven extraía sinfonías y sonatas de la chistera de su oído sordo, Pitol, a partir de "El oscuro hermano gemelo", revela que escribir literatura es completar toda una red de malentendidos, lagunas, susurros y fragmentos captados por los sentidos que exige ser completada. El arte de la ficción (acaso términos sinónimos), a través del desvío, el subterfugio, la metaforización, produce imágenes con frecuencia más vívidas que la experiencia directa que se pretende unívoca y rotunda.

Literatura: el arte de la suposición plausible.

\section{Polifonía y carnavalización}

En El desfile del amor, novela cargada de emblemas sobre los resabios del "porfiriato" vigentes aún hasta el medio siglo (quizá el más significativo de ellos lo constituyen las aspiraciones legitimistas y aristocratizantes -a veces francamente filisteas - de individuos venidos a menos en un mundo en que la cultura de masas las torna risibles), escrita en Praga y que abre la tercera parte de la obra de Pitol, el historiador mexicano Miguel del Solar (apellido de luz, vista, esclarecimiento), proveniente de Bristol, Inglaterra, en cuya universidad da clases de historia, vuelve al edificio en que vivió en su infancia, el Minerva (nombre significativo de la deidad romana de la sabiduría que instaura los privilegios de la vista), para intentar esclarecer un asesinato que ahí se produjo cuando él tenía 10 años, una "edad en que es posible recordar todo o casi todo... Y, por supuesto, recordaba muchas cosas... ¡Pero de qué absurda, desmadejada e incoherente manera!” (PITOL, 2006b, p. 15), lo que ya revela el hiato que hay entre el mero registro de los hechos y su interpretación.

Para ello, se entrevista con cuatro sobrevivientes a la noche del crimen: su tía Eduviges Briones, la parte resentida de la historia por haber perdido su influencia política; Pedro Balmorán, anticuario baldado cuyo resentimiento por haber sido ninguneado por los promotores culturales de su juventud es sublimado por una grotesca autocomplacencia; Delfina Uribe, socialité y galerista que daba las cartas en el ambiente artístico y cultural de su tiempo, y en la actualidad se consuela de su poder perdido con la maledicencia; y Emma Werfel, mediocre y apocada custodia de los acervos de su madre, la célebre hispanista Ida Werfel. Esta troupe de lenguaraces (cada capítulo de la novela está dedicado a una de esas voces), más que ayudarlo a esclarecer el pasado y comprender el México de "la Unidad Nacional" (cuando en plena segunda guerra mundial el presidente en turno, Manuel Ávila Camacho, ante la amenaza que representaban para la clase política y económica dominante las transformaciones operadas durante el cardenismo, intenta una conciliación de clases entre los grupos en disputa), lo van a confundir, revelando que "indagar una época de México equivale a abrir expedientes incompatibles." (VILLORO, 2001b, p. 54). 
A partir de este relato (en el que se cruzan el género policial, el ensayo, la novela paródica, las memorias y hasta la reflexión sobre la relación entre la historiografía y el discurso literario), en el que el asesinato del joven austriaco avecindado en México, Erich Maria Pistauer, no es desvendado, Pitol revela su concepción de la literatura: más que "el descubrimiento de la forma correcta" de contar algo que la objetividad de un conjunto de hechos empíricos impone, se trata de un acto creativo por el que el ficcionista, elemento central de mediación, busca distintas opciones de argumento, multiplicando las perspectivas por las cuales es posible acceder a potenciales sentidos que la superficie de los hechos no revela.

Una variante de ese recurso lo representa "Mephisto-Waltzer", relato escrito en Moscú en 1979. Ahí, una mujer que viaja en un vagón de tren, tras beber un somnífero para relajarse y poder dormir tranquilamente, abre una revista en la que hay un cuento de su exmarido. Están ahí, de entrada, algunos elementos que Pitol utiliza en su discurso de autor: el protagonismo del acto de la lectura, que se hace durante el viaje, y la percepción alterada, estableciendo un paralelismo entre los efectos del sedante y las fiebres tercianas de la infancia bajo el olor de la melaza y el tórrido calor tropical. Por su parte, el cuento que ella va a leer en la revista trata de un escritor escribiendo diversas versiones de un relato. En un artificio literario que recuerda el sutil arte de las Matrioshkas, dentro del cuento de Pitol una mujer lee el cuento de su marido que, a su vez, produce diversas versiones de un hecho, todas, según su mujer, condenadas al fracaso pues el escritor, víctima previsible de sus tics literarios ("Para ella la parte más interesante comenzaba en el punto donde su marido cerraba el relato." PITOL, 1983, p. 35), es derrotado por las potencialidades del relato, mostrando, por lo tanto, que las formas, por sí mismas, son impotentes, pues se tornan puro artificio.

Si en El desfile del amor los entrevistados, como dice la canción tropicalista de Tom Zé, "explican para confundir", y en el "Mephisto-Waltzer" el conjunto de versiones fracasadas de un mismo hecho dan como resultado un relato maestro, los textos de Pitol sugieren que la literatura constituye la derrota de la idea de la verdad como versión única, y contribuyen al triunfo de la verdad que la ficción puede ofrecer. Porque ésta, en su carácter complejo, así como no es lo opuesto a la verdad ni sinónimo de mentira, tampoco es la pura ilustración figural de tesis discursivas sabidas y aceptadas de antemano. A pesar de que sea problemático asociarla sin más a una búsqueda comprometida por la "verdad", ella tampoco es inocua, mero entretenimiento. Quizá sea más consecuente postular que la ficción es una actividad inherente al ser humano, una forma de cognición y un modo de relacionarse con lo real.

A ese respecto, en El concepto de ficción, Juan José Saer afirma:

Pero que nadie se confunda: no se escriben ficciones para eludir, por inmadurez o irresponsabilidad, los rigores que exige el tratamiento de la «verdad», sino justamente para poner en evidencia el carácter complejo de la situación, carácter complejo del que el tratamiento limitado a lo verificable implica una reducción abusiva y un empobrecimiento. Al dar un salto hacia lo inverificable, la ficción multiplica al infinito las posibilidades de tratamiento. No vuelve la espalda a una supuesta realidad objetiva: muy por el contrario, se sumerge en su turbulencia, desdeñando la actitud ingenua que consiste en pretender saber de antemano cómo esa realidad está hecha. (SAER, 2012, p. 11)

De esta forma, la reflexión sobre las distintas posibilidades de narrar un mismo acontecimiento, que según él le viene de haber visto el Rashomon de Kurosawa en un cineclub 
de Nueva York ("Charlando con Cervantes. Sergio Pitol”, 2017, 6' 33”), y con el que explícitamente establece una intertextualidad en El desfile del amor (en esta novela, a propósito de que Miguel del Solar comenta que todos los entrevistados le han dado testimonios que se contraponen entre sí, confundiéndolo, su primo Derny hace la siguiente reflexión: "Cada quien, como en los dramas de Pirandello o en Rashomon, tiene su propia versión de los hechos" - PITOL, 2006b, p. 174), en otra de sus dimensiones, conecta con su lectura de los autores rusos, en especial de Dostoievski, que fueron fundamentales en su formación. No se puede ignorar que en la manera poliédrica de construir las historias está la presencia de las lecciones de Bajtín sobre la "polifonía" (extraída de una lectura cuidadosa de Los hermanos Karamazov) y la "carnavalización". Como si estas reflexiones hubieran estado en el aire en la narrativa mexicana de los ochenta, en Noticias del Imperio (1987) Fernando del Paso aborda el hasta entonces olvidado "Segundo Imperio Mexicano" (1863 - 1867) y la presencia de Maximiliano de Habsburgo y Carlota de Bélgica en ese tiempo de confirmación de la república y el triunfo liberal. La novela, en la que se cruzan ensayo, historiografía, ficción y el discurso de corte autobiográfico, está construida de una pluralidad de voces. A partir de la escritura de fragmentos que se posicionan en diversos ángulos desde los que un evento histórico puede ser observado y contado (ahí puede observarse desde la ficcionalización de episodios de la historia, monólogos de figuras históricas, reflexiones sobre obras de carácter historiográfico que han abordado ese episodio, la creación de voces de personajes populares, hasta un magistral monólogo de Carlota que además de abrir y cerrar el libro, ocupa la mitad del mismo), la obra de Del Paso cuestiona las limitaciones a las que se expone toda interpretación que se quiere única.

En la presentación a Los mejores cuentos de Sergio Pitol organizados por Anagrama, Enrique Vila-Matas (que en su homenaje escribió Lejos de Veracruz, novela que lo tiene como protagonista) escribe:

Desde que leí «Vals de Mefisto» [dedicado a él por Pitol] doy varias versiones de un mismo hecho, sobre todo si ese hecho pertenece a mi vida íntima. Por ejemplo, me han preguntado muchas veces por qué me hice escritor y he contestado de mil maneras distintas, y haciéndolo me he aproximado más a la realidad que si siempre hubiera contestado con una única versión. (VILA-MATAS, 2005, p. 19)

De acuerdo con su propio testimonio, fue en Praga donde Pitol, acotado y hundido en el habla diplomática, que es el habla del poder (solemne, pomposa, hecha para decir sin comprometerse demasiado), empezó a escribir, por las noches, una novela que empezó con ese lenguaje serio, y al poco tiempo fue invadida por la parodia, lo soez y lo que él llama "el lenguaje cuartelario". ("Charlando con Cervantes. Sergio Pitol”, 2017, 18' 55")

Es bajo ese espíritu que compondrá El desfile del amor (1984), Domar a la divina garza (1988) y La vida conyugal (1990), conjunto de obras que más tarde, como ya fue dicho anteriormente, será conocido como la Trilogía del carnaval. En esas tres historias, lo paródico, lo grotesco, lo satírico y lo farsesco son la gramática y la lógica que confieren legibilidad a las historias contadas. Si en la primera las voces resentidas de la tía Eduviges Briones, del anticuario Pedro Balmorán (“el mismo que canta y baila"), de la socialité Delfina Uribe, y de la archivista Emma Werfel -personajes esperpénticos que parecen considerar que el vituperio es una rama del conocimiento-impiden que Miguel Del Solar esclarezca el asesinato de Erich Maria Pistauer ocurrido en 1943, ya en la segunda, Dante C. de la Estrella, bajo un torrencial aguacero vespertino, a la manera de "El ángel exter- 
minador", de Luis Buñuel, mantiene prisionera de su discurso enfurecido y escatológico ${ }^{14}$ a la familia Millares en su propia casa. La tercera, que cuenta la historia de una pareja que cumple con los sagrados votos matrimoniales de torturarse hasta que la muerte los separe, centra el relato en Jacqueline Cascorro, una mujer que al mejorar su nivel económico y frecuentar los altos círculos sociales de México parece haber caído en desgracia, y a la que le molesta que sus hermanos le recuerden su nombre de pila: María Magdalena.

En estos tres libros, en los que se "vindica la vulgaridad, lo escatológico, lo popular y lo populachero" (COLORADO, 2018, p. 72), Sergio Pitol se consolida como un renovador de la literatura mexicana. A semejanza de Jorge Ibargüengoitia (otro miembro de la "Generación del Medio Siglo"), que con Los relámpagos de agosto (1964) renueva la tradición de la "novela de la revolución" con esta forma paródica de abordar la clase política mexicana que capitaliza diez años de lucha armada y traiciona los ideales de justicia social al fundar las prácticas del "priísmo", la "carnavalización" utilizada por Pitol refuerza la importancia del humor en un sistema literario como es el mexicano, cuyas obras paradigmáticas tienden a la solemnidad. Construidas a partir de figuras por las que no parece revelar el menor asomo de cariño, las novelas que componen La trilogía del carnaval, verdadero ajuste de cuentas con un México que en pleno siglo XX insistía en cargar, como un sello de denominación de origen, las marcas de una sensibilidad presuntuosa forjada por la clase media "porfirista", ${ }^{15}$ revelan a un autor que, a partir de "la farsa y la deformación", parece sumamente interesado en que sus lectores observen "la caída patética y grandilocuente de sus personajes." (GARCÍA BERGUA, 2018, p. 8)

En "O narrador. Observações sobre a obra de Nikolai Leskow", Walter Benjamin afirma que dos son las figuras arquetípicas que están en el origen de la narración: una, la del viajero que viene de lugares ignotos cargado de experiencias novedosas para contar; otra, la del campesino anclado a la tierra, portavoz de una tradición que sus escuchas no conocen. ${ }^{16}$

14 Con referencias explícitas a Gogol y a Bajtín, el protagonista de la novela recita:

"Cáguelo yo duro,

o lo haga blandito,

a la luz y en lo oscuro sé mi dulce santito.” (PITOL, 2006a, p. 132.

15 A este respecto, es oportuno recordar Amor perdido (1977), magistral y sarcástico ensayo de Carlos Monsiváis (amigo íntimo e interlocutor de Pitol desde la juventud), en cuyos capítulos iniciales se realiza una incisiva radiografía de los vestigios culturales que el "porfiriato" imprimió a la vida cotidiana del país a pesar del triunfo de la Revolución de 1910 - 1920: “Si no es para anunciar una gran pasión, disponer metódicamente de "vida interior" es un lujo inadmisible. [...] hay porfiristas, un puñado de mexicanos apoderados del fin y el principio del siglo, la sociedad cortesana en un país colonial, la tradición que encarna, se preserva y multiplica como baile de carnaval donde todos fuesen ataviados para una ceremonia de coronación y hubiese la consigna de no permitir ruido alguno. [...] Buenas maneras: maneje usted la sombrilla con toda parsimonia, déle vueltas, suspire, no demuestre celo ni precipitación... [...] Criados de librea:una residencia es, siempre, un compromiso didáctico y erótico, cada cosa en su sitio, los camafeos, los armarios de nogal, los taburetes turcos, la marquetería de concha nácar, los espejos de marco dorado, las macetas de porcelana y vidrio y, en el jardín, el oporto y el cognac. Moral impecable: la honra es tu primera dote, hija mía, la honra es tu escudo y tu fortaleza, tu pronto auxilio, tu razón de ser y tu plenitud. Declaraciones (en óvalo) de los antepasados: no hemos surgido sólo para la groria de esta fotografía, ya estábamos desde el principio y si mi padre se armó de un bisabuelo fue para no dejarnos en la orfandad. ¿Ya vio usted nuestro escudo de armas?” (MONSIVÁIS, 1986, p. 18)

16 “Cuando alguien realiza un viaje, tiene algo qué contar, dice la voz del pueblo e imagina al narrador como alguien que viene de lejos. Pero con no menos placer se escucha a aquel que, viviendo honestamente de su trabajo, se quedó en casa y conoce las historias y tradiciones de su tierra. Si se quiere presentificar a estos dos grupos a través de sus representantes arcaicos, uno está encarnado por el labrador sedentario y el otro por el marino mercante." (BENJAMIN, 1980, p. 58 - trad. VL) 
A diferencia de los escritores canónicos de la literatura hispanoamericana, Pitol

Elige destinos poco frecuentados por otros escritores de su continente: Varsovia, Praga, Moscú, Georgia, Tbilisi. En su escritura hay hoteles, librerías, estaciones de trenes, aeropuertos, cafés italianos o bares polacos, museos literarios en Moscú y ópera de Pekín, una boda en Asjabad y un festival de cine en Tashkent. (DABROWSKA, 2018, p. 13)

Aventurándose por las carreteras secundarias o francamente de terracería de las literaturas europeas o asiáticas en busca de otras dicciones o modos de escribir la experiencia, sus textos han renovado la literatura no sólo mexicana, sino en español. De esta forma, el viajero vuelve a México no sólo con libros traducidos de la Europa del Este, sino también con una reactualización del realismo y de la novela de humor. Asimismo, revitaliza, en la literatura mexicana y en español, la prosa ensayística. En su Curso de literatura rusa, Vladimir Nabokob dice que "de todos los personajes que crea un gran artista, los mejores son sus lectores.” (NABOKOV, 2009, pp. 112 - 113) Quizá esa es la principal contribución de la obra de Sergio Pitol a las letras mexicanas: alterar los modos de lectura.

\section{Conclusiones. El escritor y la Biblioteca}

En los años 60, cuando las fiebres del nacionalismo menguaban y la resaca permitía bañarse no sólo dos o tres, sino muchas veces, en las mismas aguas, posibilitando un balance más complejo sobre "el mexicano" -mismo que los tratados de ontología, hasta el momento, habían sobredeterminado en la cuestión de la autenticidad del "ser"-, Augusto Monterroso (escritor nacido en Honduras, que pasó su infancia en Guatemala y toda su vida adulta en México - en cuyo sistema literario se lo suele considerar) publicó la fábula en que una rana, que quería ser auténtica, se pasaba las horas mirándose al espejo para buscar los rasgos que la particularizaban y la definían, y así poder realzar su imagen ante la mirada del otro y granjearse su aprecio.

Un día observó que lo que más admiraban de ella era su cuerpo, especialmente sus piernas, de manera que se dedicó a hacer sentadillas y a saltar para tener unas ancas cada vez mejores, y sentía que todos la aplaudían.

Y así seguía haciendo esfuerzos hasta que, dispuesta a cualquier cosa para lograr que la consideraran una rana auténtica, se dejaba arrancar las ancas, y los otros se las comían, y ella todavía alcanzaba a oír con amargura cuando decían que qué buena rana, que parecía pollo. (MONTERROSO, 2007, p. 53)

Si es verdad, como él afirmaba, que el "verdadero humorista pretende hacer pensar, y a veces hasta hacer reír” (MONTERROSO, 1991, p. 100), esta fábula alerta no sólo para los límites de la indagación sobre la identidad, sino también para lo compleja que es la relación entre literatura y espacio.

En su aparente evidencia, uno de los criterios más polémicos para catalogar y conferir valor a la literatura es situarla geográficamente. Desde el uso del término Weltliteratur (1827), de Goethe, hasta los intentos por confeccionar Historias nacionales de las literaturas, la arbitrariedad es la marca de esas denominaciones. A pesar de que Óscar Tacca, de manera oportuna, recuerde que "Historia universal resulta en la práctica sinónimo de 
europea, o, en el mejor de los casos, occidental" (TACCA, 1968, p. 56), se olvidó, sin embargo, destacar que el concepto de "Europa" es un constructo discursivo más que una realidad material: el carácter de pedigrí y prestigio con que suele utilizárselo debería hacernos recordar que (por ejemplo) probablemente la literatura francesa sea más "europea" que la letona. De la misma manera, no todos los que escriben en un determinado Estado-nación conquistan el derecho a que se los considere miembros de su literatura. Hasta hace poco, no resultaba fácil meterse al sistema literario de un país: a propósito de Zama, Juan José Saer, escritor santafecino, recordaba cómo la "literatura argentina" (marcadamente porteña hasta la década de 60 del siglo pasado), no contemplaba lugar para el mendocino Antonio di Benedetto. Del mismo modo, el centralista sistema literario mexicano en la opinión de Jorge Ruedas de la Serna ${ }^{17}$ sólo últimamente admite lo que se escribe más allá de la línea del trópico de cáncer, de ahí que los debates sobre una "literatura del Norte" de México sólo hayan hecho su aparición en los últimos años.

En su obra, Sergio Pitol asume el carácter dislocado y de extrañamiento de la literatura. Así como en su discurso de autor las lecturas que forman el imaginario e influencian la percepción pueden venir de las más variadas latitudes, mezclándose a las da la tradición local, así también el acto de la escritura constituye un dislocamiento del que escribe consigo mismo. Obligado a ser distinto del hombre de todos los días (para disipar el prejuicio del sentido común que cree que "escribir como se habla" es una muestra de alta pericia verbal, el escritor y ensayista mexicano Gonzalo Celorio recuerda: "Thomas Mann decía que la única diferencia entre el escritor y quien no lo es consiste en que al escritor le cuesta mucho trabajo escribir." - CELORIO, 2018, p. 35), el escritor, para decirlo en terminología hegeliano-marxista, se aliena en sus objetivaciones - de ahí que no sea raro que más tarde no se reconozca en sus propios escritos, como es el caso del propio Pitol, que frecuentemente disminuía los méritos de su más célebre relato de juventud, "Victorio Ferri cuenta un cuento" (1958)

Situada en el centro simbólico (que no siempre coincide con el del poder del Estado) de La Ciudad, la Biblioteca, fruto de la constante actividad organizativa y administradora del bibliotecario, es un espacio que jerarquiza, clasifica, instituye lugares, establece relaciones de parentesco, impone límites y determina las reglas del juego de exclusiones e inclusiones que sujetan los libros que ella contiene. En su autosuficiencia, ese sistema vale también para las obras que se quedaron a la intemperie. Fruto del pensamiento, los libros tienen la extraña pretensión de sobreponerse a una realidad que ayudan a comprender; reducción o síntesis (en los casos extremos, síntesis reductora), llegan a hacer creer al lector que la Biblioteca es "todo lo que hay", y nada existe fuera de ella, pues es "impensable”. Sin embargo, ella se encuentra en permanente reconstrucción. Además de que en sus estantes y galerías llegan a encontrarse hordas de quintacolumnistas carcomiendo su aparente estabilidad (¿no son esos los frecuentes hallazgos de la crítica?), del lado de afuera ella está permanentemente sitiada, acosada por los escritores y las obras que desean tomarla - lo que fatalmente acaba ocurriendo, ampliando así su corpus y modificando tanto sus jerarquizaciones internas como las tradiciones que ella contiene.

17 “En México, en cambio, predominó siempre un fuerte centralismo cultural, de modo que, hasta la fecha, el sistema literario ha dependido predominantemente del poder central. Para constatar esto basta con examinar cualquiera de nuestras historias literarias: se observará que los escritores que han entrado a formar parte del "repertorio nacional" son aquellos que o nacieron en la capital o inmigraron a ella. Los que permanecieron en la periferia por lo general no existieron para la historia literaria. Y ahora es lícito preguntarse, ¿realmente no existieron?" (RUEDAS DE LA SERNA, 2013, p. 23) 
En la serie literaria mexicana, la "Generación del Medio Siglo" representa para la crítica un tránsito entre la narrativa de corte nacionalista (como es el caso de la "novela de la Revolución") y otra que se concibe participando de un sistema-mundo - como es el caso de la novela urbana o la llamada "literatura de la Onda". En su profunda originalidad, la obra de Sergio Pitol asume explícitamente que el espacio de la literatura coincide con el del imaginario. Si la vanguardia se proponía unir literatura y vida, en Sergio Pitol el hiato entre ambas permite que la primera potencie y enriquezca a la segunda.

Ante la actual profusión de obras de carácter histórico o ensayístico, de novelas que incorporan con desparpajo el humor u ocurren en las más variadas latitudes, la crítica literaria en México vuelve a preguntarse por su "sistema literario". Siguiendo los pasos de José Luis Martínez, Álvaro Matute o Jorge Ruedas de la Serna, al indagar sobre la formación de la literatura mexicana, investigadores contemporáneos lo hacen teniendo en cuenta sus derivas contemporáneas. Considerando la riqueza de la producción ficcional reciente, habrá que preguntarse cuál es la contribución de Sergio Pitol a la renovación de esa "tradición" literaria.

Asediando la Biblioteca, tras años de fructíferos dislocamientos, el viajero regresa cargando el fuego nuevo que no es el de la destrucción, sino el que -a la manera de los antiguos aztecas, que ardía a cada 52 años en el Cerro de la Estrella- augura la renovación de la fecundidad.

\section{Referencias}

BENJAMIN, Walter. La tâche du traducteur. In: BENJAMIN, Walter. Euvres 1. Mythe et violence. Préface et traduction par Maurice Gandillac. Paris: Denoël, 1971, pp. 261 275.

O narrador. Observações sobre a obra de Nikolai Leskow. In Benjamin, Adorno, Horkheimer, Habermas. (Os pensadores). Traduções de José Luno Grünnewald... [et. al.] São Paulo: Abril Cultural, 1980, pp. 57 - 74.

BOURDIEU, Pierre. As regras da arte. Gênese e estrutura do campo literário. Trad. Maria Lúcia Machado. São Paulo: Companhia das Letras, 1996.

CALVINO, Ítalo. Las ciudades invisibles. Trad. Aurora Bernárdez. Barcelona: Minotauro, 1983.

CANDIDO, Antonio. Direito à literatura. In CANDIDO, Antonio. Vários escritos. $4^{\mathrm{a}}$ ed. São Paulo: Duas ciudades; Ouro sobre Azul, 2004, pp. 169 - 191.

CELORIO, Gonzalo. De la carrera de la edad 1. De ida. México: FCE, 2018.

"Charlando con Cervantes. Sergio Pitol." New York: CUNY TV, 30 de agosto de 2017.

Disponible en: https://www.youtube.com/watch?v=UhIO-VRwn5Y. Última consulta: 20 de agosto de 2019.

COLORADO, Alfonso. Sergio Pitol, puertas y ventanas. In: La palabra y el hombre, $\mathrm{n}^{\circ}$ 46. México: Revista de la Universidad Veracruzana, octubre-diciembre de 2018, pp. $69-73$.

CORTÉS, Hernán. Segunda Carta de Relación. In: http://www.uwosh.edu/faculty_staff/ cortes/classes/Spring2004/364/Cortes.html. 2004. Última consulta: 22 de maio de 2016. DABROWSKA, Monika. El nomadismo global de Sergio Pitol. In: La palabra y el hombre, $\mathrm{n}^{\circ}$ 46. México: Revista de la Universidad Veracruzana, octubre-diciembre de 2018, pp. $12-16$. 
GAAR, José Antonio. Adiós al lenguaje. In: La palabra y el hombre, n 46. México: Revista de la Universidad Veracruzana, octubre-diciembre de 2018, pp. 29 - 31. GARCÍA BERGUA, Ana. Sergio Pitol, el viaje como retorno. In: La palabra y el hombre, $\mathrm{n}^{\mathrm{o}}$ 46. México: Revista de la Universidad Veracruzana, octubre-diciembre de 2018, pp. $6-8$.

"Historias de vida. Sergio Pitol." México: Canal 11, 20 de febrero de 2014. Disponible en: https://www.youtube.com/watch?v=jNPb0dMZYXg. Última consulta: 20 de agosto de 2019.

JAMESON, Fredric. Las antinomias del realismo. Trad. Juanmari Madariaga. Madrid: Akal, 2018.

LEÓN-PORTILLA, Miguel. José Gaos, un gran español transterrado. Madrid: “El país”, 02 de agosto de 1989. Disponible en: https://elpais.com/diario/1989/08/28/opinion/620258410_850215.html. Última consulta, 02 de septiembre de 2019. “Más cultura. Sergio Pitol". México: TV MÁS, 20 de marzo de 2015. Disponible en: https://www.youtube.com/watch?v=NwwB8t_OBRw. Última consulta: 20 de agosto de 2019.

MONSIVÁIS, Carlos. Amor perdido. México: SEP; Ediciones ERA, 1986. (Lecturas mexicanas, 44) . La cultura mexicana en el siglo XX. Edición preparada por Eugenia Huerta. A ed. México: El Colegio de México, 2010.

MONTERROSO, Augusto. La oveja negra y demás fábulas. $12^{\mathrm{a}}$ reimpresión. México: ERA, 2007.

. Movimiento perpetuo. México: Ediciones ERA, 1991.

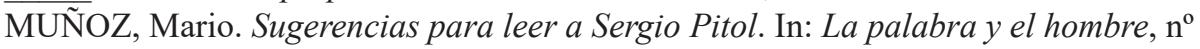

46. México: Revista de la Universidad Veracruzana, octubre-diciembre de 2018, pp. 37 -41 .

NABOKOV, Vladimir. Curso de literatura rusa. Trad. María Luisa Valseiro. Barcelona: Ediciones B, 2009.

"Palabra mayor: entrevista a Sergio Pitol". Colombia. 6 de noviembre de 2017. Disponible en: https://www.youtube.com/watch? $\mathrm{v}=\mathrm{i} 3 \mathrm{H} 9 \mathrm{DOBVeCA}$. Última consulta: $20 \mathrm{de}$ agosto de 2019.

PIGLIA, Ricardo. El último lector. Barcelona: Anagrama, 2005.

PITOL, Sergio. Discurso Sergio Pitol, Premio Cervantes 2005. 2005. Disponible en: http://www.rtve.es/rtve/20141024/discurso-sergio-pitol-premio-cervantes-2005/1035104.shtml. Última consulta: 02 de septiembre de 2019.

. Domar a la divina garza. $5^{\text {a }}$ reimpresión. Ediciones ERA, 2006a.

. El arte de la fuga. In PITOL, Sergio. Trilogía de la memoria. $1^{\text {a }}$ ed. Barcelona:

$\overline{2007 a}$, pp. $25-322$.

. El desfile del amor. $3^{\text {a }}$ reimpresión. México: 2006 b.

. El viaje. In PITOL, Sergio. Trilogía de la memoria. $1^{\mathrm{a}}$ ed. Barcelona: 2007b, pp.

$329-445$.

. La vida conyugal. $3^{\text {a }}$ reimpresión. México: Ediciones ERA, 2000.

"Mephisto-Waltzer". In Sergio Pitol. Material de lectura. México: UNAM,

1983, pp. 22 - 35. (Serie El cuento contemporáneo).

ROSADO, Juan Antonio; CASTAÑÓN, Adolfo. Los años cincuenta: sus obras y am-

bientes literarios. In: La literatura mexicana del siglo XX. FERNÁNDEZ PERERA, 
Manuel (coordinador). México: FCE; Conaculta; Universidad Veracruzana, 2008, pp. $261-310$.

RUEDAS de la Serna, Jorge. La formación de la literatura nacional (1805 - 1850). Tomo II (Los cimentos del sistema). 1ª ed. México: UNAM, 2013.

SAER, Juan José. El concepto de ficción. Buenos Aires: Seix-Barral. 2012. SPERANZA, Graciela. Autobiografía, crítica y ficción: Juan José Saer y Ricardo Piglia. In El lugar de Piglia. Crítica sin ficción. Compilación, prólogo y edición de Jorge Carrión. Barcelona: Candaya, 2008, pp. 127 - 144.

TACCA, Óscar. La historia literaria. Madrid: Gredos, 1968. (Biblioteca románica hispánica: Estudios y ensayos, 120)

VILA-MATAS, Enrique. Presentación: Has hecho girar la locura. In. PITOL, Sergio. Los mejores cuentos. Barcelona: Anagrama, 2005.

VILLORO, Juan. El traductor. In: VILLORO, Juan. Efectos personales. $1^{\text {a }}$ reimpresión. México: Ediciones ERA, 2001a, pp. $94-102$. . Pitol, los anteojos perdidos. In VILLORO, Juan. Efectos personales. $1^{\mathrm{a}}$ reimpresión. México: Ediciones ERA, 2001b, pp. 52 - 58. . El desfile del amor. Sergio Pitol. Novelas mexicanas. México: El Colegio Nacional, 29 de junio de 2016. Disponible en: https://www.youtube.com/watch?v=-UcL3p80Xpk. Última consulta: 19 de agosto de 2019.

WATT, Ian. A ascensão do romance. Estudos sobre Defoe, Richardson e Fielding. Trad. Hildegard Fiest. São Paulo: Companhia das Letras, 2010.

Recebido em: 18/10/2019; Aceito em: 10/11/2019 